\title{
PROFESSOR E ALUNO COMPARTILHANDO DA EXPERIENCIA DE ENSINO- APRENDIZAGEM: A DISCIPLINA DE ENFERMAGEM PEDIÁTRICA DA UNIVERSIDADE FEDERAL DE MATO GROSSO DO SUL
}

\author{
Myriam A. Mandetta Pettengill \\ Cristina Brandt Nunes ${ }^{2}$ \\ Maria Angélica Marchetti Barbosa ${ }^{2}$
}

Pettengill MAM, Nunes CB, Barbosa MAM. Professor e aluno compartilhando da experiência de ensino-aprendizagem: a disciplina de Enfermagem Pediátrica da Universidade Federal de Mato Grosso do Sul. Rev Latino-am Enfermagem 2003 julhoagosto; 11(4):453-60.

As autoras apresentam a experiência de ensino de enfermagem pediátrica na Universidade Federal de Mato Grosso do Sul (UFMS). Realizaram análise qualitativa das avaliações dos alunos no ano de 2000, das quais emergiram duas categorias: 'sendo uma experiência diferente' e 'modificando o olhar para a criança e família'. Concluem que a opção pela abordagem de ensino centrada na pessoa tem sido fundamental para que o aluno consiga alcançar autonomia pessoal e profissional.

DESCRITORES: ensino; aprendizado; aluno de enfermagem; educação em enfermagem

TEACHER AND LEARNER SHARING THE TEACHING-LEARNING EXPERIENCE: THE PEDIATRIC NURSING COURSE AT UNIVERSIDADE FEDERAL DE MATO GROSSO DO SUL, BRAZIL

The authors present the experience of teaching pediatric nursing at the Universidade Federal de Mato Grosso do Sul (UFMS), Brazil. They carried out a qualitative analysis of the learners' evaluation for the year 2000, from which two categories emerged: "being a different experience" and "changing the way the learners see the child and the family". They conclude that choosing the person-centered teaching approach has been of fundamental importance for the learner to achieve personal and professional autonomy.

DESCRIPTORS: teaching; learning; nursing student; nursing education

\section{PROFESOR Y ALUMNO COMPARTIENDO DE LA EXPERIENCIA DE ENSEÑANZA-APRENDIZAJ E: LA ASIGNATURA DE ENFERMERÍA PEDIÁTRICA DE LA UNIVERSIDAD DE MATO GROSSO DO SUL, BRASIL}

Las autoras presentan la experiencia de enseñanza de enfermería pediátrica en la Universidad Federal de Mato Grosso do Sul (UFMS). Realizaron un análisis cualitativo de las evaluaciones de los alumnos en el año de 2.000, de las cuales emergieron dos categorías: "siendo una experiencia diferente" y "cambiando la manera de mirar al niño y la familia". Concluyen que la opción por el abordaje de enseñanza centralizada en la persona había sido fundamental para que el alumno logre autonomía personal y profesional.

DESCRIPTORES: enseñanza; aprendizaje; alumno de enfermería; educación en enfermería

\footnotetext{
${ }^{1}$ Enfermeira Pediatra, Mestre em Enfermagem Pediátrica e Doutoranda do Programa de Pós-Graduação da Escola de Enfermagem da Universidade de São Paulo, Professor Assistente, e-mail: jcpettengill@uol.com.br; ${ }^{2}$ Enfermeira Pediatra, Mestre em Enfermagem, Professor Assistente. Universidade Federal de Mato Grosso do Sul
} 
$\boldsymbol{A}$ área de Enfermagem Pediátrica tem passado por várias transformações desde sua implantação como disciplina obrigatória nos currículos da enfermagem brasileira até nossos dias. A implantação do conteúdo de enfermagem pediátrica no Brasil só ocorreu a partir do currículo, aprovado em 1949, que foi baseado no currículo norte-americano de 1937. O ensino da assistência de enfermagem à criança foi desde o início fundamentada no ensino da patologia e das técnicas de enfermagem para atender à criança doente hospitalizada ${ }^{(1)}$.

Atualmente, o novo currículo mínimo do curso de Graduação em Enfermagem, aprovado pelo Parecer do CFE nㅇ 314/94 e homologado pela Portaria ํㅜ 1.721, de 15 de dezembro de 1994, do Ministério da Educação e do Desporto, tem como referencial a visão crítica das condições de vida, do perfil epidemiológico da população e das diretrizes das políticas de saúde voltadas para a descentralização e regionalização dos serviços e a municipalização da saúde $e^{(2)}$.

Tais diretrizes falam a favor de posturas mais renovadoras, a fim de consolidar a formação de um profissional mais crítico e consciente de seu papel social, cabendo às escolas e a seus professores a revisão e reflexão sobre as posições pedagógicas que levam à formação desse profissional ${ }^{(3)}$.

Para tornar o currículo do curso de Graduação em Enfermagem da Universidade Federal de Mato Grosso do Sul (UFMS) consoante ao currículo mínimo vigente, várias discussões e alterações na antiga grade curricular se fizeram necessárias, culminando na atual, em que as disciplinas Enfermagem Pediátrica e Estágio Supervisionado em Enfermagem Pediátrica são oferecidas na $4^{\text {a }}$ série do curso.

Apresentamos, neste artigo, a experiência de ensino de enfermagem pediátrica no referido curso, aprofundando a reflexão acerca da abordagem pedagógica implementada, porque consideramos de grande importância compartilhar a nossa experiência de ensino com aqueles que se preocupam e se dedicam na busca de avanços na maneira de ensinar as peculiaridades da criança e família no Curso de Graduação em Enfermagem. Acreditamos que, ao conhecer como o aluno de enfermagem vivencia essa abordagem de ensino, o que é significativo para ele e como percebe seu aprendizado, damos um passo importante para implementar modificações e ajustes que permitam a melhor qualidade do ensino.
Fundamentação teórica

Como docentes, sempre nos preocupamos em oferecer aos alunos ensino cuja principal qualidade seja a de valorizar a pessoa humana, ajudando-os a se desenvolverem com autonomia e responsabilidade.

Sabemos o quanto é difícil ensinar as especificidades da criança e do adolescente, fazendo o aluno avançar de um conhecimento baseado no senso comum para um conhecimento científico, assim como sensibilizá-lo para questões com as quais ainda não se encontram familiarizados, como, entre outras, a violência doméstica e as alterações na dinâmica familiar, provocadas pela doença e hospitalização do filho.

Tendo como pressuposto que, para cuidar do outro, o aluno necessita aprender a cuidar de si mesmo e a ser cuidado, acreditamos que é mister compreender o aluno como pessoa que se encontra em processo de desenvolvimento e que precisa ser auxiliado nesse período da sua formação, para que no futuro esteja mais capacitado para cuidar de pessoas.

Algumas experiências foram fundamentais para embasar nossas discussões e o planejamento das disciplinas. Um exemplo é a disciplina Enfermagem na Saúde da Criança e do Adolescente do curso de Enfermagem da Universidade de São Paulo (USP) que, a partir de 1979, adotou como referencial pedagógico a Abordagem Centrada na Pessoa, com excelentes resultados $^{(4-6)}$. Outra oportunidade foi a participação, na referida disciplina, de uma docente de nosso curso no Programa de Aperfeiçoamento de Ensino (PAE), da USP, durante o período de sua formação em pós-graduação, possibilitando-Ihe vivenciar o dia-a-dia da disciplina, bem como as discussões e avaliações - experiências que configuraram momento rico para sua formação. Além disso, deve-se mencionar a capacitação das demais docentes da disciplina em um curso de Mestrado, oferecido em convênio com a Universidade Federal de São Paulo - Escola Paulista de Medicina, que Ihes permitiu ampliar conhecimentos sobre metodologias de ensino, facilitando o processo de discussão.

$\mathrm{Na}$ área da educação, um dos mais recentes estudos que aplica os princípios pedagógicos da Abordagem Centrada no Aluno, proposta por Carl Rogers, revela que a aplicação desses princípios, além de facilitar o aprendizado, aumentou a participação dos estudantes na consecução das metas propostas ${ }^{(7)}$. 
Embasadas nessas experiências e leituras, optamos por adotar os princípios da Abordagem Centrada na Pessoa ${ }^{(8-9)}$, por refletirem nossas crenças quanto ao aluno, ao papel do professor e à maneira de ensinar. Essa metodologia de ensino permite aos alunos expressar seus sentimentos, potencializar a pessoa, liberar o indivíduo para uma escolha autônoma, resultando em mais aprendizagem, mais produtividade e mais criatividade ${ }^{(9)}$.

Nessa abordagem, os professores devem ser pessoas suficientemente seguras interiormente e em seus relacionamentos, de modo a poderem confiar na capacidade dos outros de pensar, sentir e aprender por si mesmos. São considerados facilitadores e oferecem recursos de aprendizagem que provêm de dentro de si mesmos, de suas experiências e de experiências da comunidade ${ }^{(8-9)}$.

A responsabilidade no processo de aprendizagem é compartilhada por todos os envolvidos. Os alunos desenvolvem seus próprios programas de aprendizagem ao explorarem seus interesses assumindo responsabilidade pelas conseqüências de suas escolhas ${ }^{(8-}$ 9).

Vivenciar essa maneira de aprender a aprenderé enriquecedor, propiciando crescimento para a pessoa. A aprendizagem torna-se significativa por permitir o desenvolvimento de autonomia no aluno, como pessoa que se torna responsável por seu próprio aprendizado e futuro profissional. $\mathrm{O}$ aluno adquire autoconsciência de seu processo de aprender a profissão Enfermagem ${ }^{(10)}$.

A fundamentação filosófica tem por base a convicção da liberdade humana como um ponto de partida para educação do aluno de enfermagem em formação e prática, distinguindo-se do modelo curricular dominante, que se baseia no controle e conformidade da mente humana e espírito. $O$ aluno sai de uma posição de dominação e controle, para emancipação ${ }^{(11)}$.

Apresentação das disciplinas

A carga horária total da disciplina Enfermagem Pediátrica é de 180 h, dividida em 72 h teóricas e 108 h práticas. A disciplina Estágio Supervisionado em Enfermagem Pediátrica, por sua vez, compõe-se de $72 \mathrm{~h}$ práticas. Como ambas são oferecidas, concomitantemente, cada aluno permanece $180 \mathrm{~h}$ em atividades práticas.

Os objetivos das disciplinas Enfermagem
Pediátrica e Estágio Supervisionado em Enfermagem Pediátrica são permitir ao aluno a oportunidade de conhecer a situação de vida e saúde da criança; desenvolver estratégias específicas do processo de cuidar da criança, em seu contexto familiar, e implementar, de forma sistematizada, ações preventivas, de manutenção e de recuperação da saúde da criança.

Fazem parte das disciplinas os conteúdos apresentados na Tabela 1.

Tabela 1 - Conteúdos teórico-práticos das disciplinas Enfermagem Pediátrica e Estágio Supervisionado em Enfermagem Pediátrica

1. A criança e a sociedade

a) A situação atual de morbidade e mortalidade infantil

b) O Programa de Atenção Integral à Saúde da Criança (PAISC)

c) O Programa de Saúde da Família (PSF)

d) O Estatuto da Criança e do Adolescente

e) A criança vitimizada e o trabalho infantil

f) A criança e a família - evolução histórica.

2. A criança saudável nas diversas faixas etárias - recém-nascido, lactente, toddler, pré-escolar, escolar e adolescente

a) $\mathrm{O}$ crescimento, o desenvolvimento e as necessidades da criança: sono, repouso, alimentação, brincadeira, vestuário, estimulação e prevenção de acidentes.

3. O processo de cuidar da criança e da família

a) Os tipos de abordagem do cuidar

b) O relacionamento e a comunicação com a criança e a família

c) O brinquedo terapêutico

d) O preparo para situações difíceis

e) A sistematização da assistência de enfermagem à criança

f) A consulta de enfermagem em pediatria.

4. Assistência de enfermagem à criança e família com alterações de saúde mais freqüentes em nosso meio

a) Afecções de pele e mucosa, afecções respiratórias, distúrbios nutricionais, afecções diarréicas e desidratação, câncer, intercorrências cirúrgicas, problemas cardíacos, problemas ortopédicos, afecções renais, afecções neurológicas, crianças portadoras de HIV, crianças deficientes, avaliação e tratamento da dor infantil.

5) Trabalho final

Desenvolvimento das atividades programadas

Primeiramente os alunos participam das atividades teóricas, nas quais os conteúdos básicos são desenvolvidos. Após esse período, são divididos em grupos de seis ou sete para as atividades práticas e o estágio supervisionado.

Os campos oferecidos são uma unidade de internação pediátrica, um centro de saúde, uma unidade de atendimento à criança portadora de deficiência e o Programa de Saúde da Família. Cada aluno participa das atividades práticas desenvolvidas nos diferentes campos, com acompanhamento de um professor responsável.

Após a apresentação da unidade, é realizado o primeiro grupo de discussão, quando o aluno tem 
oportunidade de refletir sobre suas expectativas e os objetivos que pretende alcançar. Depois disso, cada aluno traça seu plano de trabalho contendo os objetivos e as ações que implementará para atingi-los. Diariamente o aluno decide, junto com o professor, qual a atividade que irá realizar, com base em seu planejamento.

O aluno é acompanhado pelo professor-facilitador, que o ajuda a refletir sobre as questões e a consecução de seu plano de trabalho. Uma vez por semana ou, se necessário, mais vezes, o grupo se reúne para discutir as atividades desenvolvidas, analisando-as e propondo modificações.

Ao término do período de prática, cada aluno realiza uma auto-avaliação. Nesse momento, é convidado a analisar seu crescimento pessoal e profissional, bem como as relações com a equipe e com o professor. $O$ aluno revê seu plano de trabalho e os objetivos que havia traçado e tem a oportunidade de repensá-los. Ele analisa seu desempenho e atribui-Ihe nota de 0 a 10, conforme exigência da Universidade. O professor pode concordar ou discordar da nota atribuída pelo aluno, no momento em que discutem as avaliações.

Também faz parte da disciplina a realização de um trabalho final que pode ser apresentado por escrito, em apresentação oral, ou ainda sob a forma de pôster, cujos objetivos são desenvolver no aluno o interesse pela investigação científica na área infantil, permitir que ele reconheça temas que necessitam de maior aprofundamento teórico nessa área e prepará-lo para redigir e apresentar um trabalho científico.

Ao final, tendo o aluno cumprido as etapas teóricas e práticas na disciplina, é realizada uma reunião para discussão e avaliação final. Cada aluno faz uma autoanálise e escreve aquilo que lhe foi significativo em relação à experiência de ensino, aos docentes e à criança e família.

\section{METODOLOGIA}

Utilizamos como fonte de coleta de dados as autoavaliações escritas realizadas pelos alunos ao término das disciplinas Enfermagem Pediátrica e Estágio Supervisionado em Enfermagem Pediátrica. Buscamos assegurar aos alunos os princípios éticos da Resolução 196/96. Desse modo, foi solicitado a cada um o consentimento para utilizar sua auto-avaliação, sendo-lhes assegurado que as análises das auto-avaliações não teriam qualquer relação com a nota final da disciplina. Cada auto-avaliação foi copiada na íntegra, tendo sido eliminado o nome do aluno, garantindo-Ihe o anonimato. Todos os alunos concordaram que sua auto-avaliação fosse objeto de estudo.

O instrumento de auto-avaliação era composto por uma pergunta norteadora: conte-nos como foi sua experiência de aprendizagem na disciplina e como você percebeu a relação com o professor, a criança e família e a equipe de trabalho.

A análise dos dados, buscando a compreensão do fenômeno, foi orientada pelo modelo proposto por Forghieri $^{(12-13)}$. Em um primeiro momento, realizamos leitura atenta dos discursos dos sujeitos, na íntegra, familiarizando-nos com o todo, penetrando na vivência de cada um, tentando obter os significados atribuídos por ele. Em seguida, foram realizadas novamente a leitura e releitura atenta de cada discurso, na busca de unidades de significado. A seguir, foram procuradas as convergências e divergências em cada discurso, agrupando as unidades de significado semelhantes e que se mostravam constantes. Realizou-se a comparação dos significados na busca de elementos comuns e, ao encontrá-los, foram utilizados para caracterizar a vivência para o grupo de sujeitos estudados. Os agrupamentos desses significados possibilitaram a reflexão sobre as experiências relatadas, sendo reunidas em subtemas. Como esses subtemas expressavam componentes em comum, foram organizados formando os temas desse estudo. Desse modo, as descrições ingênuas expressadas pelos sujeitos foram analisadas e possibilitaram a compreensão do fenômeno, na perspectiva dos pesquisadores.

\section{RESULTADOS}

Foram analisadas trinta e nove avaliações realizadas pelos alunos no ano 2000.

A análise das avaliações revelou dois temas que retratam a experiência do aluno: sendo uma experiência diferente e modificando a maneira de cuidar da criança e família.

A aprendizagem do aluno de enfermagem revelase como sendo uma experiência diferente, na qual ele tem pela primeira vez a oportunidade de traçar seus próprios objetivos, tornando-se responsável por seu 
aprendizado. Ele atribui grande parte dessa conquista à atitude do professor, percebido como alguém que está junto dele nessa caminhada, dando-Ihe suporte e ajudando-o a enfrentar as situações que se apresentam. Considera essa uma experiência significativa por permitir seu crescimento como pessoa e como profissional.

Atribui à abordagem utilizada na disciplina a conquista de autonomia e fortalecimento pessoais, tornando-se sujeito do próprio aprendizado, com capacidade para refletir criticamente e buscar novos caminhos.

Ao prestar assistência, ele também se coloca em posição de igualdade com a criança e família, aproximando-os do cuidado, das tomadas de decisão, e começa a repensar sobre as questões que envolvem o cuidar. $\mathrm{O}$ aluno torna-se mais sensibilizado ao cuidado, identificando nas interações com a criança e família os elementos do cuidar, tendo a oportunidade de ampliar o conceito de cuidar. Como conseqüência, o aluno vai modificando a maneira de cuidar da criança e da família, percebendo-se importante para o cuidado e sentindo-se recompensado por ter cumprido sua missão.

'Sendo uma experiência diferente'

Para o aluno, a experiência de aprendizagem na disciplina Enfermagem Pediátrica e Estágio Supervisionado é inédita, por nunca haver ele vivenciado uma oportunidade de aprender de maneira tão intensa e envolvente, de modo a participar ativamente das decisões e escolhas.

O aluno percebe seu crescimento como pessoa e como profissional de maneira contínua durante as atividades de estágio, não apenas no campo emocional, vencendo seus medos e inseguranças, como, também, no campo científico e tecnológico, buscando conhecimentos e preparando-se para cuidar da criança. Sabe que tem limitações, porém, tem a certeza de que está mais forte para vencer as barreiras interiores e aprender a lidar com situações que considera difíceis, como o medo. Afirma que o estágio possibilita-lhe crescimento e fortalecimento como pessoa e como ser humano, jamais conseguido em experiências anteriores.

O aluno acredita que seu crescimento e a experiência significativa de aprendizagem devem-se, em grande parte, ao professor. Ele percebe o professor como facilitador do aprendizado, como um dos elos mais importantes para o aprendizado: ressalta-Ihe as atitudes ponderadas e o relacionamento de igual para igual que esse estabelece, no qual não há julgamentos ou pressões, sentindo-se o aluno, por isso, à vontade para questionar, discordar e procurar as próprias respostas às suas dúvidas, num processo de aprendizagem conduzido com tranqüilidade. Percebe não haver a tão temida pressão que estava acostumado a receber, o que the propicia crescimento como nunca imaginara obter no desenrolar de qualquer estágio. Segundo o aluno, foi fundamental o professor estar sempre presente e disponível, ajudando-o em momentos difíceis e instigando a busca de conhecimento para agir nas situações.

Um dos pontos pelo qual o aluno percebe o estágio como sendo diferente é o fato de descobrir os próprios objetivos, ao ser convidado a estabelecê-los no início das atividades, tendo a consecução desses assegurada de acordo com seu ritmo. $O$ aluno revela ter ficado perplexo com o fato de ter sido convidado a traçar seus próprios objetivos durante o desenvolvimento das atividades de estágio, aspecto desconhecido em estágios anteriores. Essa experiência, diferente das demais a que estava habituado, modifica seu comportamento.

Para tornar-se responsável pelo próprio aprendizado o aluno compreende que é preciso tomar decisões e fazer escolhas, as quais o levarão a caminhos completamente diferentes. Como ele não está acostumado com essa maneira de aprender, sente-se desconfortável e desorientado, ficando ansioso e temeroso de não corresponder às expectativas do professor, embora, ao mesmo tempo, estimule-se com a possibilidade de poder direcionar seu aprendizado.

Quando percebe que alcançou seus próprios objetivos, superando as expectativas, o aluno torna-se mais confiante, aprendendo a planejar suas atividades e a direcionar seu próprio aprendizado com autonomia, o que o faz acreditar que vai levar esse aprendizado para a vida profissional.

'Modificando sua maneira de cuidar da criança e família'

O movimento do aluno em direção à família se inicia quando, ao se relacionar com a família, percebe a importância da interação enfermeiro-criança-família. O vínculo que o aluno vai estabelecendo com a família o faz perceber que é preciso elevá-la à condição de parceira do cuidado, saindo de uma posição passiva, para sujeito do 
próprio cuidado. O aluno percebe o sofrimento da família, nesse momento de crise, e direciona todos os esforços para ajudá-la.

O aluno tem oportunidade para repensar o conceito de cuidar ao vivenciar as experiências com a criança e família. Primeiro ele percebe o quanto é difícil cuidar da criança nos mais diferentes contextos, que é preciso ganhar a confiança tanto da criança como da família. Aos poucos ele vai identificando, na prática, os elementos do cuidar, tais como se colocar no lugar da criança e da família, ser verdadeiro, respeitar o momento da criança e da família, assim como ter cautela e paciência para realizar o cuidado, o que lhe permite compreender que cuidar não é somente a realização de cuidados e procedimentos técnicos.

À medida que vai vivenciando a experiência na disciplina, o aluno amplia sua concepção e maneira de cuidar, indo além da patologia e das técnicas. Seu olhar e seu papel profissional em relação à criança e família são modificados, com o apoio do professor-facilitador. $\mathrm{O}$ aluno transforma o medo e a insegurança iniciais em sentimento positivo de confiança.

A experiência é significativa, fazendo com que o aluno se sinta recompensado, importante e vitorioso por ter participado do cuidado à criança e família. Ele sofre ao interagir com a criança, presenciando seu sofrimento, mas se sente recompensado por ter podido contribuir para amenizar um pouco esse sofrimento. O sorriso da criança e o reconhecimento por parte da família despertam nele alegria, satisfação e confiança.

\section{DISCUSSÃO}

O aluno de enfermagem vivencia a disciplina percebendo-a como sendo diferente das demais que havia experienciado no curso, porque lhe é assegurado liberdade para fazer escolhas. Esse ponto é fundamental para que ocorra a aprendizagem significativa ${ }^{(8-9)}$. Trata-se de ter liberdade e responsabilidade para direcionar o próprio aprendizado. O aluno torna-se mais amadurecido, crescendo com a experiência, tendo oportunidade de desenvolver um senso crítico mais acurado em relação às experiências vivenciadas anteriormente, o que the proporciona condições para escolher aquela que melhor explicita sua maneira de ser. Forma-se assim um profissional de enfermagem mais crítico e com condições de melhor avaliar as situações que vivenciar, o que the permitirá direcionar suas próprias decisões. O aluno desenvolve capacidades racionais e morais do futuro enfermeiro, assim como emocionais, expressivas e pessoais $^{(11)}$.

Para que a missão de cuidar se torne legítima e central, é preciso que ocorram mudanças significativas na educação em enfermagem. $O$ foco do ensino deve alterar-se do treinamento para a educação, da técnica para a compreensão, do conteúdo estrito para a tomada de consciência crítica $^{(14)}$.

Para o aluno, quando ele se percebe capaz de estabelecer os próprios objetivos, direcionando seu aprendizado, aumenta sua autoconfiança, o que o ajuda na tomada de decisões acerca do seu futuro profissional. $O$ aluno adquire mais autonomia, o que permite perceberse como um ser ativo e consciente do seu papel.

É evidente, nos textos sobre ensino, a preocupação em buscar ações mais intensas para a formação de profissionais conscientes de cidadania, independência de pensamento e capacidade crítica. Falase muito na formação de cidadãos que saibam ler o mundo em que estão inseridos e que sejam capazes de transformar esse mundo para melhor ${ }^{(15)}$. No entanto, a perspectiva da "transmissão" e a crença de que basta ter "domínio do conteúdo" são, infelizmente, as mais presentes nos cursos superiores ainda hoje ${ }^{(16)}$.

Quando o aluno modifica sua maneira de cuidar da criança e família, ampliando sua concepção sobre o significado do cuidar, fica aberto às possibilidades de mudanças, resultando em aprendizagem duradoura e plena de significados. Ao verbalizar seus sentimentos e as mudanças internas que percebe, decorrentes da experiência, tem-se o momento de ocorrência de uma aprendizagem significativa. Já o aluno que não está aprendendo limita-se, basicamente, a verbalizar críticas ao que se passa fora dele, sem relacionar tais fatos com sua pessoa ${ }^{(4)}$.

A aprendizagem alcança profundidade quando ocorre a partir de situações chamadas experiências significativas; a educação está onde surge o significado, o qual não pode ser dado ou transmitido, mas, sim, adquirido $^{(17)}$.

A pedagogia apresenta diferentes abordagens pedagógicas, desde o ensino centrado no professor até outras totalmente centradas no aluno. Mais recentemente observa-se um processo de interação permanente entre alunos, professor e objeto de conhecimento, de forma que 
o professor provoque questionamentos concretos, colocando à disposição fontes e materiais, sendo ele próprio uma "fonte" a interagir com as idéias dos alunos (devolvendo questões, apontando alternativas e propondo novas relações) ${ }^{(18)}$.

Um ponto forte da experiência do aluno foi a oportunidade de ser compreendido, o que corrobora com a asserção de outros autores ${ }^{(6)}$, que o aluno reproduz aquilo que vive: se ele passa pela experiência de ser compreendido, procura se esforçar para compreender também. Esse é um aspecto que chamou nossa atenção, pois percebemos que o aluno começou a cuidar da criança e família, da mesma maneira como se percebia cuidado pelo professor. Acreditamos que tal aspecto é de fundamental importância em uma profissão que tem como propósito cuidar de pessoas. Se o aluno passa pela experiência de ensino, compartilhando experiências com o professor, sendo respeitado e compreendido, e vivenciando uma interação, terá mais chances de repetir esse comportamento ao cuidar do paciente e família, assim como ao se relacionar com os membros da equipe de enfermagem.

O pensamento de um importante pesquisador representa exatamente aquilo que acreditamos ser necessário para que o professor consiga realizar plenamente seu papel de educador: "a arte mais importante do mestre é a de fazer brotar alegria no estudo e no conhecimento... O professor só pode esperar atingir o seu público na medida em que ele próprio é atingido por esse público; na medida em que o percebe enquanto desejo ativo e se sente enriquecido por ele"(18).

\section{CONSIDERAÇÕES FINAIS}

Os temas emergentes revelaram que a experiência do aluno de enfermagem é significativa, pois contém elementos preconizados pela abordagem centrada no aluno, tais como: 0 aluno consegue superar as dificuldades e cresce com a experiência; adquire mais autonomia e responsabilidade pelo processo de aprendizagem; amplia

\section{REFERÊNCIAS BIBLIOGRÁFICAS}

1. Collet N, Rocha SMM. Transformações no ensino das técnicas em enfermagem pediátrica. Goiânia (GO): AB Editora; 1996.

2. Ministério da Educação e do Desporto (BR). Conselho Federal de Educação. Parecer 314/94. Currículo mínimo para o curso de enfermagem. Brasília; 1994. e modifica sua concepção de cuidar, indo de uma abordagem centrada na patologia para a abordagem centrada na criança e família; o professor cumpre seu papel de facilitador da aprendizagem, propiciando ao aluno que aprenda a aprender.

Professor e aluno compartilham a experiência ensino-aprendizagem, que configura um momento de intenso crescimento para ambos. Há evidente melhora nas interações professor-aluno, baseadas em confiança recíproca.

A vivência na disciplina favoreceu uma mudança no aluno, em seu jeito de pensar, sentir e agir no mundo. Ampliou sua concepção de cuidar e a maneira como olha para a criança e a família, bem como sua compreensão sobre a doença. O aluno se torna mais capacitado para pensar e refletir sobre o vivido em um contexto de experiências significativas. Ao perceber sua transformação interior, torna-se mais seguro de si e mais consciente de seu papel profissional.

Selecionamos o trecho de uma avaliação em que uma aluna reflete sobre seu crescimento. Em suas palavras, é possível apreender o quanto a aprendizagem foi significativa para sua vida pessoal e profissional: $\mathrm{Com}$ certeza o meu crescimento neste estágio foi perceptível. Aprendi muito além da patologia, de assistência. Aprendi o que é o 'cuidar' em todos os seus aspectos e abrangência... como solucionar os problemas para alívio da mãe e da criança... como curar feridas não só externas como as internas que são freqüentes nas crianças hospitalizadas. Os objetivos traçados no início do estágio foram realmente alcançados... procurarei levar esse aprendizado para a vida profissional... aprendi a não olhar apenas a patologia, a medicação, o curativo, o exame físico, tudo, individualmente, mas, sim, ver a criança e sua família, o que está acontecendo na vida e na cabeça de todos diante de uma doença que muda o percurso de tudo o que eles viviam ... aprendi a lutar por uma pessoa que passa por dificuldades e a entender até mesmo seus momentos de isolamento ... acredito que o sentido da profissão do enfermeiro tem que seguir o que eu vi e vivi durante este estágio ... além de tudo devemos ser sinceros e dar escolhas ao paciente e sua família ... me colocar no lugar do paciente e membro de sua família, é a melhor forma de saber como prestar o cuidado de enfermagem.

3. Vendrúsculo DMS, Manzolli MC. Currículo na e da enfermagem: por onde começar e recomeçar? Rev Latinoam enfermagem 1996; 4(1):55-70.

4. Ribeiro CA, Martins DMR, Huerta EPN, Moraes E, Angelo M. A disciplina enfermagem pediátrica: avaliação pelos alunos de uma nova metodologia de ensino. Rev Esc Enfermagem USP 1982; 16(2):181-92. 
5. Huerta E, Angelo M, Ribeiro MO, Horta ALM. O curso de enfermagem pediátrica I na Escola de Enfermagem da USP. Rev Esc Enfermagem USP 1985; 19(3):247-62.

6. Angelo M, Bousso RS, Santos MadaC, Horta AldeM, Caldas MAM. Mudanças identificadas pelo aluno de enfermagem, resultantes da vivência em uma abordagem centrada na pessoa. Rev Esc Enfermagem USP 1989; 23(3):363-8.

7. Coelho J Sobrinho. Do que somos capazes? relato de uma experiência pedagógica. Tese (Livre-Docência). São Paulo (SP): Escola de Comunicação e Artes/USP; 2001.

8. Rogers CR. Liberdade para aprender. 4.ed. Belo Horizonte (MG):Interlivros; 1978.

9. Rogers CR. Para além do divisor de águas: para onde agora? In: Rogers CR. Um jeito de ser. São Paulo (SP): EPU; 1983.

10. Pettengill MAM. O sentido do cuidar da criança e da família na comunidade: a experiência do aluno de enfermagem. [dissertação]. São Paulo (SP): Escola de Enfermagem/USP; 1998.

11. Bousso RS, Merighi MAB, Rolim MA, Riesco MLG, Angelo, M. Estágio curricular em enfermagem: transição de identidades. Rev Esc Enfermagem USP 2000; 34(2):218-5.

12. Forghieri YC. Contribuição da fenomenologia para 0 estudo das vivências. Rev Bras Pesq Psicol 1989; 1(2):7-29. 13. Forghieri YC. Psicologia fenomenológica: fundamentos, método e pesquisas. São Paulo: Pioneira; 1993.

14. Angelo M. Educação em enfermagem: a busca da autonomia. Rev Esc Enfermagem USP 1994; 28 (1):11-4.

15. Chassot A. (Re)Pensando ações docentes: sobre como professoras e professores podem transformar o seu fazer pedagógico. In: Moraes VRP, organizadora. Melhoria do ensino e capacitação docente. Porto Alegre (RS): Editora da Universidade; 1996. p.87-101.

16. Bordas MC. Apresentação. In: Moraes VRP, organizadora. Melhoria do ensino e capacitação docente. Porto Alegre (RS): Editora da Universidade; 1996.

17. Menegat R. Sala de aula: espaço para aprender, espaço para pensar. Uma abordagem a partir do ensino de estratigrafia em geociências. In: Moraes VRP, organizadora. Melhoria do ensino e capacitação docente. Porto Alegre (RS): Editora da Universidade; 1996. p.102-16.

18. Fischer BTD. Prática docente na universidade: uma questão menor? In: Moraes VRP, organizadora. Melhoria do ensino e capacitação docente. Porto Alegre (RS): Editora da Universidade; 1996.p.46-3. 